\title{
Knowledge Assessment of Working Women Regarding Breast Cancer / Control and Prevention in Kirkuk Technical Institute
}

\author{
Wafa Mahmood Jasim \\ Assist Prof / Community Health Dept/ Kirkuk Technical Institute-Northern Technical University / Iraq
}

\begin{abstract}
Breast cancer is the most common cancer in women both in the developed and less developed world In Iraq, it is the commonest type of female malignancy, accounting for approximately one-third of the registered female cancers according to the latest Iraqi Cancer Registry.

A descriptive cross-sectional study was conducted on working women in Kirkuk Technical Institute during the period from $1^{\text {st }}$ April till $30^{\text {th }}$ June / 2016 to assess their knowledge regarding breast cancer prevention and control methods.

The total number of included studied women was 71 from different scientific departments after distributing a special questionnaire form and face to face interview was done after receiving the written agreements to participating in the study.

Majority of working women are technical (52.2\%), married (74.7\%) aging above 40 years (47.8\%) with employment years above 15 years $(50.0 \%)$.

Both electrical and survey dept. go with the establishing of breast cancer prevention at adulthood after fully maturated $(44 \%, 45 \%)$ respectively in comparison to $57.7 \%$ of study women from electronic dept. go with the starting of cancer prevention at the birth of a first child .

The main recommendation of the study is that further researches should be done because there is a need for increased efforts towards developing and widely available cancer educational program that focuses on the main preventive measures and encouraging the women with breast disease, not only providing them with information but also for the ability to make her decision to control the disease
\end{abstract}

Key words : Knowledge, breast cancer, assessment, control and prevention.

\section{Introduction}

Women play a critical role in maintaining the health and well being of their communities because families and communities health is tied to the health of women. Woman illness or death has serious and farreaching consequences for their children, families, and communities $^{(1)}$.

Among women, breast cancer is the most common cause of cancer mortality accounting for $16 \%$ of cancer deaths in adult women ${ }^{(2)}$. Breast cancer is a serious life-threatening public health problem of great concern. Increases in the incidence of breast cancer are being observed in both industrialized and developing world (3).

WHO promotes breast cancer control methods within the national cancer control program which is directed for both non- communicable diseases and other related health consequences his program includes (prevention, early detection of the disease, diagnosis, treatment, rehabilitation with the assistance of

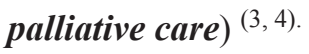

The key strategies for population-based breast cancer control are : 
1 - Increasing the awareness of the general public about this health problem.

\section{2- Appropriate policies and health programs ${ }^{(5)}$.}

Nowadays countries with low and middle income facing a double burden of breast cancer which is regarded as a top killer in women aging over 30 years old. These countries need further specific strategic methods that concentrated for effective ways of disease prevention ${ }^{(5)}$.

A study was done by Nada etal during 2014 mentioned that breast cancer constitutes about one fourth of the reported cancer cases among Iraqi population which is regarded the main cause of death and each year many women are exposed to the vicious ramifications of breast cancer which include death if left untreated or the negative outcomes that would experience, cosmetically and psychologically, after exposure to surgical intervention ${ }^{(6)}$.

Another study was done in Iraq about the breast cancer incidence trends from 2000- 2009 which reported that the disease incidence of all female breast cancer in Iraq (all ages) has risen and there is a rapid increase in the age-specific incidence rate among the age group 60-69. However, this disease among Iraqi women still affects younger age groups than their counterparts in developed countries ${ }^{(7)}$.

Reduction in the incidence of breast cancer needs control of both modifiable risk factors with the effective integrated preventive measures that promote ( intake of the healthy diet, daily physical activity, alcohol, and weight control ) which eventually have a direct impact for the future outcomes. ${ }^{(8,9) \text {. }}$

In more recent years, many studies have indicated the effect of diet and other behaviors on the occurrence of breast cancer. These additional risk factors are environmental factors such as tobacco use, radiation, endocrine disturbance and shift work ${ }^{(10)}$.

The main three important screening tests usually considered for controlling and preventing the disease which is 1 - clinical breast examination (CBE) 2-X-ray mammography 3- breast self-examination (BSE). In industrial countries, breast cancer mortality is declining where screening mammography is the standard for care. BSE is appealing as a patient-centered, noninvasive screening procedure which allows women to become more comfortable with their own bodies $(11,12)$.
The aim of the study: to assess the knowledge of working women regarding breast cancer control and prevention methods

\section{Methodology-}

\section{1- Ethical issues}

Official agreements were taken from Kirkuk Technical Institute before establishing the study

\section{2- Study design and setting:-}

A descriptive cross-sectional study was carried out in Kirkuk Technical Institute on three scientific departments (Electronic, Electrical, and Survey).

\section{3- Study sample and sampling method:-}

A randomly selected sample from 71 working women ( 25 from the electronic department and 26 from the Electrical department and 20 from the Survey Department).

A specific special questionnaire form was distributed to them after receiving their written consent and the data was collected by interviewing with the study women after complete explanation of the main objectives of the study.

\section{4- Study period :}

The study was conducted during the period from $1^{\text {st }}$ April till 30 $0^{\text {th }}$ June / 2016.

\section{5- Data collection tool:-}

Certain designed prepared questionnaire form has been conducted by the investigator utilizing a recent updated related literature to the study subject included three main parts:-

Part-1- Demographic characteristics like ( age, employment year, type of work, and martial status ).

Part-2- Information about their knowledge regarding disease control and preventive measures with the main risk factors ). Part -3- Their knowledge about the specific time for starting the prevention of breast cancer.

\section{6- Reliability of the questionnaire form:-}

The data was presented to (4) experts in different fields, they were (2) Clinical physicians, (1) Community physicians and (1) statistical experts. 
Inclusion criteria: Any married woman

Exclusion criteria: History with chronic diseases such as hypertension, Diabetes's mellitus, or renal disease.

\section{7- Statistical analysis of data:-}

The information regarding each participant was transferred into a code sheet and the data entry was done using a computer Pentium IV and the statistical analysis was calculated by mine tab program $/ 2016^{(13)}$.

All the statements with Yes and No answer, number and percent will be calculated.

Chi-square test was used to detect the relation between the studied variables and the level of significance is taken at level 5\% $(\mathrm{P}<0.05)$.

\section{Results}

The total number of working women are 89 distributed among three scientific departments.

The number of women responded to study was 71 and the response rate was $(79.7 \%)$.

Table (1): Socio- demographic characteristics of the study women

\begin{tabular}{|c|c|c|c|}
\hline \multicolumn{2}{|c|}{ Socio- demographic parameter } & Number(N=71) & Percent \\
\hline Age group in year & $\begin{array}{l}<20 \\
20-25 \\
25-30 \\
35-40 \\
>40\end{array}$ & $\begin{array}{l}8 \\
10 \\
19 \\
24 \\
10\end{array}$ & $\begin{array}{l}11.2 \\
14.3 \\
26.7 \\
33.8 \\
14.0\end{array}$ \\
\hline Employment years & $\begin{array}{l}5-10 \text { years } \\
11-15 \text { years } \\
>15 \text { years }\end{array}$ & $\begin{array}{l}9 \\
23 \\
39\end{array}$ & $\begin{array}{l}12.6 \\
32.4 \\
\mathbf{5 5 . 0}\end{array}$ \\
\hline Type of work & $\begin{array}{l}\text { Official } \\
\text { Technical } \\
\text { Teacher }\end{array}$ & $\begin{array}{l}12 \\
37 \\
22\end{array}$ & $\begin{array}{l}16.9 \\
\mathbf{5 2 . 2} \\
30.9\end{array}$ \\
\hline Marital status & $\begin{array}{l}\text { Single } \\
\text { Married }\end{array}$ & $\begin{array}{l}18 \\
53\end{array}$ & $\begin{array}{l}25.3 \\
74.7\end{array}$ \\
\hline
\end{tabular}

Table 1 shows that most of the study women are technical (52.2\%) aging between 35-40 years (33.8 \%) with employment years above 15 years $(55.0 \%)$, married (74.7\%).

Table (2): Frequency distribution of study women according to family history and type of relationship

\begin{tabular}{|c|c|c|c|c|c|c|c|c|}
\hline \multirow{3}{*}{ No } & \multicolumn{2}{|l|}{ Items } & \multicolumn{2}{|l|}{ Yes } & \multicolumn{2}{|l|}{ No } & \multicolumn{2}{|l|}{ Total } \\
\hline & \multirow{2}{*}{\multicolumn{2}{|c|}{$\begin{array}{l}\text { 1-Family history of } \\
\text { breast cancer } \\
7\end{array}$}} & No. & $\%$ & No. & $\%$ & No. & $\%$ \\
\hline & & & 9.8 & 64 & 90.2 & 71 & 100.0 & \\
\hline \multirow{2}{*}{\multicolumn{2}{|c|}{$\begin{array}{l}\text { 2- Relation of breast cancer with the relatives } \\
4\end{array}$}} & Mother & \multicolumn{2}{|c|}{ Sister } & \multicolumn{2}{|l|}{ Aunt } & \multicolumn{2}{|c|}{ Grand mothe } \\
\hline & & \multicolumn{2}{|l|}{3} & 0 & & 0 & & \\
\hline
\end{tabular}


Table 2 indicated that $90.2 \%$ of study women had a negative family history of breast cancer and only $9.8 \%$ of them had a positive history of breast cancer with a first degree ( mother and sister).

Table (3): Study women distribution according to their knowledge about the risk factors, preventive and control measures for breast cancer.

\begin{tabular}{|c|c|c|c|c|c|}
\hline \multirow{2}{*}{ Knowledge parameter } & \multicolumn{4}{|c|}{ Number of working women $(=71)$} & \multirow{2}{*}{ *P value } \\
\hline & yes & $\%$ & No. & $\%$ & \\
\hline $\begin{array}{l}\text { Risk factors of breast cancer } \\
\text { a- Aging factor } \\
\text { b- Contraceptives pills } \\
\text { c- Life style } \\
\text { d- Family history }\end{array}$ & $\begin{array}{l}12 \\
21 \\
10 \\
3\end{array}$ & $\begin{array}{l}26.1 \\
45.6 \\
21.8 \\
6.5\end{array}$ & $\begin{array}{l}11 \\
7 \\
5 \\
2\end{array}$ & $\begin{array}{l}44.0 \\
28.0 \\
20.0 \\
8.0\end{array}$ & 0.000 \\
\hline Total & 46 & 100.0 & 25 & 100.0 & \\
\hline $\begin{array}{l}\text { Control measures : } \\
\text { a- Advanced educational program } \\
\text { b- Raised general public awareness } \\
\text { c- Control risk factors like contraception } \\
\text { d- Regular cheek up }\end{array}$ & $\begin{array}{l}19 \\
10 \\
8 \\
2\end{array}$ & $\begin{array}{l}48.7 \\
25.6 \\
20.6 \\
5.1\end{array}$ & $\begin{array}{l}12 \\
8 \\
5 \\
7\end{array}$ & $\begin{array}{l}37.5 \\
25.0 \\
15.6 \\
21.8\end{array}$ & 0.240 \\
\hline Total & 39 & 100.0 & 32 & 100.0 & \\
\hline $\begin{array}{l}\text { Preventive guidelines: } \\
\text { a- Screening by mammography } \\
\text { b- Modifying healthy life style } \\
\text { c- Regular breast self exam } \\
\text { d- Breast clinical exam }\end{array}$ & $\begin{array}{l}18 \\
20 \\
13 \\
3\end{array}$ & $\begin{array}{l}29.4 \\
39.2 \\
25.5 \\
5.8\end{array}$ & $\begin{array}{l}6 \\
3 \\
4 \\
7\end{array}$ & $\begin{array}{l}30.0 \\
15.0 \\
20.0 \\
35.0\end{array}$ & 0.000 \\
\hline Total & 51 & 100.0 & 20 & 100.0 & \\
\hline
\end{tabular}

Table 3 shows that there was a statistically significant agreement among study women knowledge regarding risk factors was for contraceptive pills $(45.6 \%),(48.7 \%)$ for the advanced educational program as a control measures and (39.2\%) for modifying healthy life style as a preventive measure for breast cancer prevention with a $\mathrm{P}$ value $=0.000$.

Table 4: Frequency distribution of study women according to their knowledge about the specific time for starting the prevention of breast cancer

\begin{tabular}{|c|c|c|c|c|c|c|c|c|}
\hline \multirow{3}{*}{$\begin{array}{l}\text { Specific time for starting the prevention } \\
\text { of breast cancer }\end{array}$} & \multicolumn{6}{|c|}{$\begin{array}{l}\text { Study women } \\
\mathrm{N}=71\end{array}$} & \multirow{3}{*}{ Total } & \multirow{3}{*}{$\begin{array}{l}\mathbf{P} * \\
\text { value }\end{array}$} \\
\hline & \multicolumn{2}{|c|}{$\begin{array}{l}\text { Electronic dept. } \\
\mathrm{N}=26\end{array}$} & \multicolumn{2}{|c|}{$\begin{array}{l}\text { Electric dept. } \\
\mathrm{N}=\mathbf{2 5}\end{array}$} & \multicolumn{2}{|c|}{$\begin{array}{l}\text { Survey dept } \\
\mathrm{N}=\mathbf{2 0}\end{array}$} & & \\
\hline & No. & $\%$ & No. & $\%$ & No. & $\%$ & & \\
\hline $\begin{array}{l}\text { 1- Child hood before and during breast } \\
\text { development }\end{array}$ & 2 & $7.7 \%$ & 7 & $28 \%$ & 4 & $20 \%$ & $\begin{array}{l}13 \\
(18.3 \%)\end{array}$ & 0.166 \\
\hline
\end{tabular}


Cont... Table 4: Frequency distribution of study women according to their knowledge about the specific time for starting the prevention of breast cancer

\begin{tabular}{|l|l|l|l|l|l|l|l|}
\hline $\begin{array}{l}\text { 2- Young adult hood before fully } \\
\text { maturation of the breast }\end{array}$ & 5 & $19.3 \%$ & 1 & $4 \%$ & 5 & $25 \%$ & $\begin{array}{l}11 \\
(15.5 \%)\end{array}$ \\
\hline 3- Adult hood after the breast fully mature & 4 & $15.3 \%$ & 11 & $44 \%$ & 9 & $45 \%$ & $\begin{array}{l}24 \\
(33.9 \%)\end{array}$ \\
\hline 4- The birth of a women first child & 15 & $57.7 \%$ & 6 & $24 \%$ & 2 & $10 \%$ & $\begin{array}{l}23 \\
(32.3 \%)\end{array}$ \\
\hline
\end{tabular}

${ }^{*} \chi^{2}-$ test was used

Table 4 shows that both electrical and survey dept. go with the establishing of breast cancer prevention at adulthood after fully maturated $(44 \%, 45 \%)$ respectively in comparison to $57.7 \%$ of study women from electronic dept. go with the starting of cancer prevention at the birth of a first child with a $\mathrm{P}$ value $=0.015$

\section{Discussion}

Regarding the family history of breast cancer, the study shows that most of the working women had a negative family history of breast cancer. This result goes with the American cancer society (ACS)report about the disease / $2007^{(14)}$ The report stated that any women who had a history of breast cancer in her family is more prone to be a risk factor for it and this will lead gradually to increase the level of education about the disease occurrence

Shambhavi etal conducted a study in Mangalore, Karnataka / India to assess the teacher's knowledge regarding breast cancer and to find the association between the level of knowledge and some selected demographic variables. They found that the highest number of school teachers $(60 \%)$ were in the age group between $25-35$ years and least were about $>55$ years of age $(6 \%)^{(15)}$.

Concerning the general knowledge of the breast cancer, the current study show the about half of study women knowledge regarding risk factors was for contraceptive pills and for the advanced educational program as a control measures. This result may be explained because of better information sources from the scientific references and the declaration of the Ministry of health on the television about the danger and risk factors of the disease.
Samir /2011 (16) conducted a study in the college of nursing / University of Sulaimani who found that the general informative background of study students regarding breast cancer, clinical manifestation, risk factors and control measures were ranged between highly significant and moderate. He explained that because of the student scientific study and general information in their college.

Another study was prepared by Alkhasawneh /2007 (17) at Pamukkale University Denizli hospital / Jordan among nurses. $\mathrm{H}$ e found that 74 (57.6\%) of them were correctly knew at least four risk factors of the disease and the increasing age $72 \%$, familial history $94.4 \%$, childlessness $85.6 \%$, absence of breastfeeding $82.4 \%$, and taking birth control pill or hormone replacement therapy $50.4 \%$ were well-known risk factors. However, a small percentage of them believed that early menarche $23.2 \%$ and late menopause $28.8 \%$ were the risk factors of breast cancer. He discussed these results because of breast cancer is being considered as a disease of the developed countries and much efforts with strong emphasis had been given to this issue in addition to that further preventive and control measures was conducted against breast cancer.

A similar study was conducted by Nada et al. / $2012^{(18)}$ in Kirkuk University about knowledge, attitude and practice towards breast cancer and breast selfexamination as the most effective preventive measure towards breast cancer.

They found that the general knowledge about breast cancer and the practice of breast -self-examination was relatively well in Kirkuk yet the positive attitude towards learning the screening techniques and the intention to teach others were fairly encouraging hey recommended 
for promoting public health awareness campaigns through various media.

Dr. Golditiz et al / $2015^{(19)}$ published a study about the prevention of breast cancer mentioned that control and prevention should start early in life because nearly $25 \%$ of breast cancer patient is diagnosed in women younger than age 50 years in developed countries and $22 \%$ of it is diagnosed in premenstrual women and is often aggressive than cancer diagnosed in postmenopausal women . They recommended for adaptation of a specific strategy to decrease cancer risk by calculated how much the differences would occur in a sample of women .

A study was done by Coleman / $2008^{(20)}$ to assess the survival rate of breast cancer. He found that the disease range was from $80 \%$ or more in North America, Sweden, and Japan to reach up to $60 \%$ in Middle income- countries and very low in low incomecountries which reach to $40 \%$ and they explained these differences because of lack of preventive measures like early detection health programs which later on lead to increase the proportion of women complaining of late and advanced stage of the disease with the lack of adequate specific diagnosis of the disease .

\section{Conclusion}

Informative background for studied women was good but still, there is a defect in disease prevention and time for early detection.

Ethical Clearance: The Research Ethical Committee at scientific research by ethical approval of both environmental and health and higher education and scientific research ministries in Iraq

Conflict of Interest: The authors declare that they have no conflict of interest.

Funding: Self-funding

\section{References}

1- Bener A, Alwash R, Miller CJ, Denic S and Dunn EV. Knowledge, attitude and practice related to breast cancer screening; a survey of Arabic women J Cancer Educ.2001; 16(4): 215 - 220.

2- Odusanya O O. Breast cancer: knowledge, attitude, and practices of female school teachers in Lagos Nigeria. Breast J. 2001; 7(3): 171 - 175.

3- WHO, Cancer control: knowledge into action: WHO guide for effective programmes: early detection, 2007 .

4- WHO (2008). The global burden of disease: 2004 update.

5- Yip $\mathrm{CH}$, Guideline implementation for breast healthcare in low- and middle-income countries: early detection resource allocation. Cancer, 2008; 113, 2244-56.

6- Nada A S, Faisal H F. Promoting Clinical Breast Examination as A screening Tool for Breast Cancer in Iraq, Iraqi National Journal of Nursing Specialties, 2014; 27 (1): 4.

7- Al-Hashimi MM, Wang XJ . Breast cancer in Iraq, incidence trends from 2000-2009, Asian Pac J Cancer Prev. 2014;15(1):281-6 .

8- Anderson BO, Guideline implementation for breast healthcare in low-income and middle-income countries: overview of the Breast Health Global Initiative Global Summit 2007. Cancer, 2008; 113, 2221-43.

9- Danaei G. Causes of cancer in the world: comparative risk assessment of nine behavioral and environmental risk factors. Lancet, 2005; 366, 1784-93.

10- Sasco AJ: Epidemiology of breast cancer: an environmental disease? Apmis2001;109:321-

32.

11- Jemal A, Siegel R, Ward E . "Cancer statistics, 2008". CA Cancer J Clin 58 (2): 71-96.

12- Rao RSP, Nair S, Nair NS, Kamath VG: Acceptability and effectiveness of a breast health awareness programme for rural women. Indian Journal of Medical Sciences 2005, 59:398-402 .

13-. Parkin DM, Bray F, Ferlay J, Pisani P. Global Cancer Statistics . CA Cancer J Clin. 2005;55:74108.

14- American cancer society (ACS). "Cancer facts and figures" Atlanta, a available online, February. 2007; 12 .

15- Shambhavi, Shanthi S.,. Vinutha M D'Souza . Assessment of knowledge on breast cancer among the teachers in selected schools of Mangalore Medical Science 2014; 3(4): 297-298 .

16- Samir Y. Lafi, Assessment of female students knowledge concerning breast cancer in the college of nursing / University of Sulaimani . Al- Taqani J. 
2011; 24(7): 41-43 .

17- Alkhasawneh IM. Knowledge and practice of breast cancer screening among Jordanian nurses. Oncology Nursing Forum. 2007;34(6):1211-1217.

18- Nada A.S. Alwan, Jwad K.A. Al-Diwan, Wafa' M. Al-Attar, Raghad A. Eliessa. Knowledge ,and practice towards breast cancer \& breast self examination in Kirkuk University, Iraq. Asian Pacific Journal of Reproduction 2012; 1(4): 308311.
19- Colditz AG, Bohlke K Catherine S B, Breast cancer risk accumulation starts early - Prevention must also, Breast Cancer Res Treat. 2014; 145(3): 567-579.

20- Coleman MP, Cancer survival in five continents: a worldwide population-based study(CONCORD). Lancet Oncol, 2008 ; 9, 730 56. 